JURNAL GIZI DAN DIETETIK INDONESIA

Vol. 4, No. 3, September 2016: 123-128
Tersedia online pada: http://ejournal.almaata.ac.id/index.php/IJND

DOI : http://dx.doi.org/10.21927/ijnd.2016.4(3).123-128

\title{
Aktivitas fisik berhubungan dengan kejadian obesitas pada anak sekolah dasar
}

\author{
Children's physical activity was related with obesity in elementary children
}

\author{
M. Zamzani', Hamam Hadi ${ }^{1}$, Dewi Astiti
}

\begin{abstract}
Backgrounds: The increasing prevalence of obesity is caused by imbalance between energy input to energy output. Physical activity in children both at school and at home plays an important role in determining the nutritional status of children, including the risk of obesity.

Objectives: To determine the relationship between children physical activity with obesity in Ngebel Elementary School, Tamantirto Kasihan Bantul.

Methods: This study was an observational study with cross sectional design. The study population were all children grades 3, 4, and 5 Ngebel Elementary School, Tamantirto Kasihan Bantul. These samples included 96 children who met the inclusion and exclusion criteria obtained with less total sampling technique. Weight of children were measured using digital bathroom, and height was measured using microtoise collected by trained enumerators. Physical activity data were obtained using a physical activity questionnaire. Nutritional status data were calculated using the WHO Software Anthro 2005, univariate analysis using frequency distribution and bivariate analysis using Fisher's Exact Test. Data were analyzed using software of statistic.

Results: Physical activity had a significant relationship with the incidence of obesity in children, with $p$ value 0.009 (<0.05) with OR 5.69 (95\% Cl: 1.42 to 22.65). In other words children who did moderate to severe activity $\leq 1$ hour/day had 5 times higher chance to be obese than children with moderate to severe activity $>1$ hour/day.

Conclusions: Physical activity has a significant association with obesity.
\end{abstract}

KEYWORDS: physical activity, obesity, elementary school children

\begin{abstract}
ABSTRAK
Latar belakang: Peningkatan prevalensi obesitas disebabkan oleh adanya ketidakseimbangan antara masukan energi dengan keluaran energi. Aktivitas fisik pada anak-anak baik di sekolah maupun di rumah berperan penting dalam penentuan status gizi anak, termasuk risiko terjadinya obesitas.

Tujuan: Untuk mengetahui hubungan antara aktivitas fisik dengan kejadian obesitas pada anak Sekolah Dasar Negeri Ngebel, Tamantirto Kasihan Bantul.

Metode: Penelitian ini merupakan penelitian observasional dengan rancangan cross sectional. Populasi penelitian adalah semua anak kelas 3, 4, dan 5 SDN Ngebel, Tamantirto Kasihan Bantul. Sampel penelitian berjumlah 96 anak yang memenuhi kriteria inklusi dan eksklusi diperoleh dengan teknik total sampling. Berat anak-anak diukur dengan menggunakan timbangan injak digital, sedangkan tinggi badan diukur menggunakan microtoise dibantu oleh enumerator terlatih. Data aktivitas fisik diperoleh menggunakan kuesioner aktivitas fisik. Data status gizi dihitung dengan menggunakan software WHO Anthro 2005, analisis univariat menggunakan distribusi frekuensi, dan analisis bivariat menggunakan Fisher's Exact Test. Data dianalisis dengan menggunakan perangkat lunak statistik.

Hasil: Hasil analisis menunjukkan aktivitas fisik memiliki hubungan yang signifikan dengan kejadian obesitas pada anak dengan nilai p value 0,009 (<0,05) dengan nilai OR 5, 69 (95\% Cl: 1,42-22,65), dengan
\end{abstract}

\footnotetext{
${ }_{1}^{1}$ Prodi S1 IImu Gizi, Fakultas IImu-ilmu Kesehatan Universitas Alma Ata Yogyakarta, e-mail: zamzanimoch@gmail.com
} 
kata lain anak yang melakukan aktivitas sedang-berat $\leq 1$ jam/hari berpeluang 5 kali lebih besar untuk mengalami obesitas daripada anak dengan aktivitas sedang-berat $>1$ jam/hari.

Kesimpulan: Aktivitas fisik memiliki hubungan secara bermakna dengan obesitas.

KATA KUNCI: aktivitas fisik, obesitas, anak $S D$

\section{PENDAHULUAN}

Di negara berkembang seperti Indonesia, masalah obesitas tidak hanya terjadi pada keluarga yang berpenghasilan tinggi tetapi juga terjadi pada keluarga yang berpenghasilan rendah dan menengah. Pada sebagian orang, obesitas pada anak sering dianggap sebagai lambang kemakmuran (1).

Prevalensi obesitas di Provinsi Daerah Istimewa Yogyakarta (DIY) menurut data tahun 2007 menunjukkan prevalensi berat badan lebih berdasarkan kategori IMT/U pada anak usia 6-14 tahun yaitu $7,6 \%$ pada anak laki-laki dan $4,8 \%$ pada anak perempuan (2). Data tahun 2010 menunjukkan bahwa prevalensi obesitas pada anak usia 6-12 tahun baik laki-laki maupun perempuan adalah 7,8\% (3).

Obesitas disebabkan oleh adanya ketidakseimbangan antara masukan energi dengan keluaran energi. Meningkatkan aktivitas fisik di luar rumah seperti bersepeda, kejar-kejaran, sepakbola, mengikuti kegiatan ekstrakurikuler di sekolah, dan mengurangi perilaku sedentary behavior seperti nonton TV, bermain playstation, dapat mengurangi risiko obesitas pada anak (4). WHO mengeluarkan rekomendasi tentang anjuran aktivitas fisik yang dilakukan. Orang muda direkomendasikan untuk melakukan aktivitas fisik sedang-berat sekurangkurangnya 60 menit sehari dalam seminggu (5). Penelitian sebelumnya di Manado menyatakan bahwa menonton televisi dan atau bermain video game memiliki kontribusi yang signifikan terhadap kejadian obesitas pada anak jika dilakukan lebih dari 1 jam setiap harinya (6).

Hasil studi pendahuluan yang telah dilakukan di SDN Ngebel, Tamantirto, Kasihan, Bantul terhadap 106 anak didapatkan hasil sebanyak 16\% mengalami obesitas, $13,2 \%$ mengalami overweight, $53 \%$ berstatus gizi normal, dan $17 \%$ mengalami underweight. Grafik pertumbuhan yang digunakan sebagai acuan adalah grafik Kemenkes RI tahun 2011 dengan standar deviasi >2 (IMT/U z-score) (7).
Penelitian ini bertujuan untuk mengetahui hubungan antara aktivitas fisik dengan kejadian obesitas pada anak Sekolah Dasar Negeri Ngebel, Tamantirto, Kasihan, Bantul.

\section{BAHAN DAN METODE}

Jenis penelitian ini adalah observasional dengan rancangan cross sectional. Penelitian ini dilakukan di SDN Ngebel, Tamantirto, Kasihan, Bantul dan dilaksanakan pada bulan JanuariFebruari 2016. Populasi dalam penelitian ini adalah seluruh anak kelas 3,4 , dan 5 dengan jumlah sampel yang diperoleh menggunakan teknik total sampling sebanyak 96 anak yang memenuhi kriteria inklusi dan eksklusi.

Variabel bebas dalam penelitian ini adalah aktivitas fisik sedangkan variabel terikat adalah obesitas. Data sekunder yang meliputi data gambaran umum sekolah, alamat sekolah, serta jumlah kelas dan jumlah siswa diperoleh dari pihak terkait sekolah.

Data primer yang terdiri dari data karakteristik subjek penelitian diperoleh menggunakan kuesioner terstruktur. Data tinggi badan diukur dengan menggunakan microtoise dengan ketelitian $0,1 \mathrm{~cm}$ dan berat badan anak diukur dengan timbangan injak digital dengan ketelitian 0,1 kg. Data aktivitas fisik diperoleh dengan menggunakan kuesioner yang telah diadopsi dari penelitian sebelumnya tentang perilaku sedentari sebagai faktor risiko kejadian obesitas pada anak sekolah dasar di Kota Yogyakarta dan Kabupaten Bantul tahun 2013 (8). Data dikumpulkan dengan menanyakan pertanyaan yang tertera dalam kuesioner kepada responden oleh peneliti dibantu 5 enumerator (mahasiswa S1 Prodi Gizi semester 8) yang sebelumnya sudah diberi pengarahan dan pelatihan. Setelah semua data terkumpul, data dianalisis secara bivariat menggunakan Fisher's Exact Test dengan menggunakan perangkat lunak statistik. 
HASIL

\section{Karakterisik subjek penelitian}

Karakteristik subjek penelitian yang meliputi kelompok usia, jenis kelamin, jumlah anggota rumah tangga, pendidikan ibu, pekerjaan ibu, pendidikan ayah, pekerjaan ayah, dan penghasilan per bulan dapat dilihat pada Tabel 1.
Berdasarkan Tabel 1 diketahui bahwa distribusi usia, jenis kelamin, jumlah anggota rumah tangga, pendidikan ibu, pekerjaan ibu, pendidikan ayah, pekerjaan ayah, dan penghasilan per bulan pada anak yang obesitas dan tidak obesitas tidak berbeda signifikan $(p>0,05)$.

Tabel 2 menunjukkan bahwa 60,4\% anakanak sekolah mempunyai aktivitas sedang-berat

Tabel 1. Karakteristik subjek penelitian antara kelompok obesitas dan tidak obesitas

\begin{tabular}{|c|c|c|c|c|}
\hline \multirow{3}{*}{ Karakteristik } & \multicolumn{2}{|c|}{$\begin{array}{c}\text { Status gizi } \\
\end{array}$} & \multirow{3}{*}{$\begin{array}{l}\text { Total } \\
\mathbf{n}(\%)\end{array}$} & \multirow{3}{*}{$\mathbf{p}$} \\
\hline & Tidak obesitas & Obesitas & & \\
\hline & $\mathrm{n}(\%)$ & $n(\%)$ & & \\
\hline \multicolumn{5}{|l|}{ Kelompok usia } \\
\hline 9-11 tahun & $54(56,2)$ & $9(9,4)$ & $63(65,6)$ & \multirow[t]{2}{*}{0,352} \\
\hline $12-14$ tahun & $30(31,2)$ & $3(3,1)$ & $33(34,4)$ & \\
\hline \multicolumn{5}{|l|}{ Jenis kelamin } \\
\hline Laki-laki & $45(46,9)$ & $7(7,3)$ & $52(54,2)$ & \multirow[t]{2}{*}{0,757} \\
\hline Perempuan & $39(40,6)$ & $5(5,2)$ & $44(45,8)$ & \\
\hline \multicolumn{5}{|l|}{ Jumlah anggota rumah tangga } \\
\hline$>4$ orang & $24(25,0)$ & $6(6,2)$ & $30(31,2)$ & \multirow[t]{2}{*}{0,123} \\
\hline$\leq 4$ orang & $60(62,5)$ & $6(6,2)$ & $66(68,8)$ & \\
\hline \multicolumn{5}{|l|}{ Pendidikan ibu } \\
\hline Tinggi ( $\geq S M A)$ & $40(41,7)$ & $7(7,3)$ & $47(49,0)$ & \multirow[t]{2}{*}{0,487} \\
\hline Rendah ( $\leq$ SMP) & $44(45,8)$ & $5(5,2)$ & $49(51,0)$ & \\
\hline \multicolumn{5}{|l|}{ Pekerjaan ibu } \\
\hline Buruh/buruh tani & $17(17,7)$ & $1(1,0)$ & $18(18,8)$ & \multirow[t]{5}{*}{0,641} \\
\hline Karyawan swasta & $7(7,3)$ & $1(1,0)$ & $8(8,3)$ & \\
\hline PNS/TNI/POLRI & $2(2,1)$ & 0 & $2(2,1)$ & \\
\hline Wiraswasta & $14(14,6)$ & $1(1,0)$ & $15(15,6)$ & \\
\hline IRT/Tidak bekerja & $44(45,8)$ & $9(9,4)$ & $53(55,2)$ & \\
\hline \multicolumn{5}{|l|}{ Pendidikan ayah } \\
\hline Tinggi ( $\geq S M A)$ & $45(46,9)$ & $7(7,3)$ & $52(54,2)$ & \multirow[t]{2}{*}{0,757} \\
\hline Rendah ( $\leq$ SMP) & $39(40,6)$ & $5(5,2)$ & $44(45,8)$ & \\
\hline \multicolumn{5}{|l|}{ Pekerjaan ayah } \\
\hline Petani/peternak/nelayan & $2(2,1)$ & 0 & $2(2,1)$ & \multirow[t]{5}{*}{0,713} \\
\hline Buruh/buruh tani & $44(45,8)$ & $5(5,2)$ & $49(51,0)$ & \\
\hline Karyawan swasta & $20(20,8)$ & $5(5,2)$ & $25(26,0)$ & \\
\hline Wiraswasta & $16(16,7)$ & $2(2,1)$ & $18(18,8)$ & \\
\hline Tidak bekerja & $2(2,1)$ & 0 & $2(2,1)$ & \\
\hline \multicolumn{5}{|l|}{ Penghasilan perbulan } \\
\hline$\leq$ Upah Minimum Regional & $63(65,6)$ & $6(6,2)$ & $69(71,9)$ & \multirow[t]{2}{*}{0,076} \\
\hline >Upah Minimum Regional & $21(21,9)$ & $6(6,2)$ & $27(28,1)$ & \\
\hline
\end{tabular}

*Signifikan $(p<0,05)$

Tabel 2. Hubungan aktivitas fisik dengan kejadian obesitas

\begin{tabular}{|c|c|c|c|c|c|}
\hline \multirow[b]{2}{*}{$\begin{array}{l}\text { Aktivitas } \\
\text { fisik }\end{array}$} & \multicolumn{2}{|c|}{ Status gizi } & \multirow[b]{2}{*}{$\begin{array}{l}\text { Total } \\
\mathrm{n}(\%)\end{array}$} & \multirow[b]{2}{*}{$\mathbf{p}$} & \multirow[b]{2}{*}{$\begin{array}{c}\text { OR } \\
(95 \% \mathrm{Cl})\end{array}$} \\
\hline & $\begin{array}{c}\text { Tidak obesitas } \\
\mathbf{n}(\%)\end{array}$ & $\begin{array}{c}\text { Obesitas } \\
n(\%)\end{array}$ & & & \\
\hline $\begin{array}{l}\text { Sedang-berat } \\
>1 \text { jam/hari } \\
\leq 1 \text { jam/hari }\end{array}$ & $\begin{array}{l}55(57,3) \\
29(30,2)\end{array}$ & $\begin{array}{l}3(3,1) \\
9(9,4)\end{array}$ & $\begin{array}{l}58(60,4) \\
38(39,6)\end{array}$ & 0,009 & $\begin{array}{c}5,69 \\
(1,42-22,65)\end{array}$ \\
\hline Total & $84(87,5)$ & $12(12,5)$ & $96(100)$ & & \\
\hline
\end{tabular}

*Signifikan $(p<0,05)$

Analisis menggunakan Uji Fisher's Exact Test 
Tabel 3. Perbedaan rata-rata durasi aktivitas fisik antara kelompok obesitas dan tidak obesitas

\begin{tabular}{|c|c|c|}
\hline $\begin{array}{c}\text { Variabel } \\
\text { (menit/hari) }\end{array}$ & 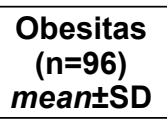 & $\begin{array}{c}\text { Tidak obesitas } \\
(n=96) \\
\text { mean } \pm \text { SD }\end{array}$ \\
\hline Aktivitas ringan & $57,6 \pm 11,8$ & $37,7 \pm 11,1$ \\
\hline Aktivitas sedang & $32,6 \pm 29,2$ & $34,7 \pm 18,5$ \\
\hline Aktivitas berat & $28,7 \pm 26,5$ & $34,8 \pm 18,8$ \\
\hline
\end{tabular}

$>1 \mathrm{jam} /$ hari. Hasil analisis menunjukkan bahwa aktivitas fisik dinyatakan berhubungan secara statistik dengan kejadian obesitas pada anak yang dibuktikan dengan diperoleh nilai $p$-value 0,009 $(<0,05)$ dan OR 5,69 (95\% Cl: 1,42-22,65). Dengan demikian, hipotesis penelitian diterima bahwa anak dengan aktivitas fisik sedang-berat $\leq 1$ jam/hari meningkatkan risiko terjadinya obesitas.

Berdasarkan Tabel 3 diperoleh data rata-rata durasi aktivitas ringan pada siswa obesitas lebih tinggi dibandingkan siswa tidak obesitas, sedangkan rata-rata aktivitas sedang dan berat lebih tinggi pada siswa tidak obesitas.

\section{BAHASAN}

\section{Hubungan aktivitas fisik dengan kejadian obesitas}

Berdasarkan hasil analisis bivariat diketahui bahwa $60,4 \%$ anak-anak sekolah melakukan aktivitas fisik sedang-berat $>1$ jam/hari (Tabel 2). Hasil uji Fisher's menunjukkan ada hubungan antara aktivitas fisik dengan kejadian obesitas pada anak yang dibuktikan dengan nilai $p=0,009(<0,05)$ dan OR 5,69 (95\% Cl: 1,42-22,65). Dengan kata lain, anak yang melakukan aktivitas sedang-berat $\leq 1 \mathrm{jam} /$ hari berpeluang 5 kali lebih besar untuk mengalami obesitas daripada anak dengan aktivitas sedangberat $>1$ jam/hari.

Penelitian ini sejalan dengan penelitian yang dilakukan sebelumnya pada anak SD di Palembang tahun 2011 yang menunjukkan bahwa ada hubungan yang signifikan antara aktivitas fisik dengan obesitas $(p=0,005)$ dengan nilai OR 2,4 . Hal ini berarti kelompok murid yang mempunyai aktivitas fisik ringan atau dan sedang mempunyai risiko untuk menderita obesitas 2,4 kali dibandingkan kelompok murid yang mempunyai aktivitas fisik berat (9). Hasil penelitian lain juga menemukan bahwa aktivitas fisik yang rendah memiliki hubungan yang signifikan dengan cadangan lemak tubuh yang tinggi (10).

Suatu studi berjudul hubungan aktivitas fisik dengan kejadian obesitas pada anak SD di Kota Manado mendapatkan nilai OR: 3,59 (95\% Cl: 1,565 $-8,238)$. Hal ini berarti anak dengan aktivitas fisik ringan memiliki risiko sebesar 3 kali menjadi obes dibandingkan anak dengan aktivitas ringan atau berat. Hasil uji statistik menunjukkan nilai $p=0,004$ yang artinya ada hubungan yang signifikan antara aktivitas fisik dengan kejadian obesitas (11). Hasil penelitian sebelumnya pada anak SD Swasta di Kota Medan tahun 2008 mendapatkan hasil bahwa aktivitas fisik merupakan salah satu faktor yang signifikan berpengaruh terhadap kejadian obesitas pada anak dari lima faktor lainnya yang signifikan (12).

\section{Durasi aktivitas fisik dengan obesitas}

Diperoleh data rata-rata durasi aktivitas ringan pada siswa obesitas lebih tinggi dibandingkan siswa tidak obesitas, sedangkan rata-rata aktivitas sedang dan berat lebih tinggi pada siswa tidak obesitas (Tabel 3). Hal ini sejalan dengan penelitian sebelumnya bahwa ada perbedaan durasi aktivitas fisik antara anak obesitas dan tidak obesitas (13). Hasil penelitian lain juga menemukan bahwa anak-anak yang obes secara signifikan memiliki akumulasi total perhitungan accelerometer harian untuk aktivitas sedang dan aktivitas berat yang lebih rendah dibandingkan anak-anak yang tidak obes (14). Hal ini didukung pula dengan sebuah penelitian di Texas yang menunjukkan bahwa siswa yang memiliki durasi latihan fisik kurang dari tiga hari per minggu beresiko untuk mengalami obesitas (15).

Obesitas pada anak SD Negeri Ngebel, Tamantirto, Kasihan, Bantul dapat disebabkan oleh beberapa hal, antara lain: rendahnya aktivitas fisik di sekolah, minimnya ekstrakurikuler sehingga menurunkan kegiatan-kegiatan yang dilakukan oleh anak, berkurangnya rasa tertarik anak untuk bermain di luar rumah setelah pulang sekolah karena mereka lebih memilih untuk menonton televisi atau bermain game yang menyebabkan aktivitas ringan menjadi lebih tinggi dibandingkan aktivitas sedang bahkan 
tidak terdapat siswa yang melakukan aktivitas berat. Anak-anak yang mempunyai aktivitas fisik di dalam rumah seperti halnya aktivitas berbasis layar dilaporkan mempunyai risiko lebih tinggi untuk mengalami obesitas dibandingkan anak dengan aktivitas berbasis layar rendah. Penelitian sebelumnya di Kota Yogyakarta dan Kabupaten Bantul tahun 2013 pada anak sekolah dasar mendapatkan hasil bahwa anak yang menonton TV $\geq 2$ jam /hari memiliki peluang 3,28 kali lebih besar untuk menjadi obesitas sebelum dikontrol variabel lain (13). Pola aktivitas yang kurang menyebabkan jumlah kalori yang dibakar lebih sedikit dibandingkan kalori yang diperoleh dari makanan yang dikonsumsi, sehingga berpotensi menimbulkan penimbunan lemak berlebih di dalam tubuh (14).

Upaya meningkatkan aktivitas fisik sejak anakanak termasuk usia saat pra sekolah, akan dapat menjaga agar anak-anak tetap memiliki aktivitas fisik yang cukup dalam upaya pencegahan obesitas. Penelitian sebelumnya di Ohio mendapatkan hasil bahwa lama bermain di luar rumah merupakan alat ukur langsung terhadap aktivitas fisik anak-anak usia pra sekolah (16).

\section{KESIMPULAN DAN SARAN}

Sebagian besar responden dalam penelitian ini berusia 9-11 tahun dengan prevalensi murid laki-laki sebesar $65,6 \%$ dan murid perempuan $54,2 \%$. Prevalensi anak yang mengalami obesitas sebanyak $12,5 \%$. Tingkat aktivitas fisik pada anak lebih didominasi pada aktivitas sedang-berat $>1$ jam/hari sebanyak $60,4 \%$. Hasil penelitian ini menunjukkan ada hubungan yang bermakna antara aktivitas fisik dengan kejadian obesitas.

Berdasarkan kesimpulan di atas, ada beberapa saran yaitu bagi institusi sekolah memberikan opsi kegiatan ekstrakurikuler yang beragam seperti sepak bola, bulu tangkis, pencak silat, tenis meja dan bola voli agar siswa lebih tetarik untuk mengikuti kegiatan sehingga dapat menurunkan risiko terjadinya obesitas. Bagi keluarga dan masyarakat dapat memberikan dukungan pada anak untuk lebih banyak melakukan aktivitas di luar rumah seperti bersepeda, sepak bola, bulu tangkis, bola kasti serta mengikuti kegiatan ekstrakurikuler di sekolah dan mengurangi aktivitas di dalam rumah seperti nonton TV dan main game untuk mengontrol berat badan anak agar tidak mengalami obesitas.

\section{RUJUKAN}

1. Tiala, PRAEM, Tanudjaja N, Kalangi R. Hubungan antara aktivitas fisik dengan lingkar pinggang pada siswa obes sentral. 2013;1(1):455-60.

2. Kementerian Kesehatan Republik Indonesia. Standar antropometri penilaian status gizi anak. Jakarta: Direktorat Bina Gizi; 2011.

3. Badan Penelitian dan Pengembangan Kesehatan Republik Indonesia. Riset kesehatan dasar 2010. Jakarta: Badan Penelitian dan Pengembangan Kesehatan Kementerian Kesehatan RI; 2010.

4. Anggraini L. Hubungan tingkat aktivitas fisik terhadap status gizi pada anak usia prasekolah. Universitas Diponegoro; 2014.

5. WHO. Global recommendations on physical activity for health [Internet]. 2010. Available from: http://apps.who.int/iris/bitstream/10665/4 4399/1/9789241599979_eng.pdf

6. Tando M, Harikedua T. Aktivitas fisik dan pola makan dengan obesitas sentral pada tokoh agama di Kota Manado. GIZIDO. 2012;4(1):289-98.

7. Arundhana AI, Hadi $\mathrm{H}$, Julia M. Perilaku sedentari sebagai faktor risiko kejadian obesitas pada anak sekolah dasar di Kota Yogyakarta dan Kabupaten Bantul. J Gizi dan Diet Indones (Indonesian J Nutr Diet. 2016;1(2):71.

8. Retnaningsih, Oktariza. Pengaruh aktivitas fisik terhadap kejadian obesitas pada murid. J Pembang Mns. 5(2).

9. Angel L, Nelly M, Franly O. Hubungan aktivitas fisik dengan kejadian obesitas pada anak sekolah dasar di Kota Manado. J Keperawatan. 2013;1(1):1-4.

10. Dencker M, Thorsson O, Karlsson MK, Lindén C, Wollmer P, Andersen LB. Daily physical activity related to aerobic fitness and body fat in an urban sample of children. Scand $\mathrm{J}$ Med Sci Sports [Internet]. 2008 Dec;18(6):728-35. Available from: http://www.ncbi.nlm.nih.gov/ pubmed/18248550 
11. Simatupang. Pengaruh pola konsumsi, aktivitas fisik, dan keturunan terhadap kejadian obesitas pada siswa sekolah dasar swasta di Kecamatan Medan Baru Kota Medan. Universitas Sumatera Utara Medan; 2008.

12. Trost SG, Kerr LM, Ward DS, Pate RR. Physical activity and determinants of physical activity in obese and non-obese children. Int $\mathrm{J}$ Obes [Internet]. 2001 Jun;25(6):822-9. Available from: http://www.nature.com/doifinder/10.1038/ sj.ijo.0801621

13. Astiti $D$, Hadi H, Julia M. Pola menonton televisi sebagai faktor risiko obesitas pada anak di sekolah dasar Kota Yogyakarta dan Kabupaten
Bantul. J Gizi dan Diet Indones (Indonesian J Nutr Diet. 2016;1(2):110.

14. Wahyu, Genis G. Obesitas pada anak. Yogyakarta: B First-Bentang Pustaka; 2009.

15. Pérez A, Hoelscher DM, Springer AE, Brown HS, Barroso CS, Kelder SH, et al. Physical activity, watching television, and the risk of obesity in students, Texas, 2004-2005. Prev Chronic Dis [Internet]. 2011 May;8(3):A61. Available from: http://www.ncbi.nlm.nih.gov/ pubmed/21477501

16. Faizah Z. Faktor risiko obesitas pada murid sekolah dasar usia 6-7 tahun di Semarang. Universitas Dipenogoro; 2014. 